\title{
The consequences of tobacco tax on household health and finances in rich and poor smokers in China: an extended cost-effectiveness analysis
}

Stéphane Verguet, Cindy L Gauvreau, Sujata Mishra, Mary MacLennan, Shane M Murphy, Elizabeth D Brouwer, Rachel A Nugent, Kun Zhao, Prabhat Jha, Dean TJamison

\section{Summary}

Background In China, there are more than 300 million male smokers. Tobacco taxation reduces smoking-related premature deaths and increases government revenues, but has been criticised for disproportionately affecting poorer people. We assess the distributional consequences (across different wealth quintiles) of a specific excise tax on cigarettes in China in terms of both financial and health outcomes.

Methods We use extended cost-effectiveness analysis methods to estimate, across income quintiles, the health benefits (years of life gained), the additional tax revenues raised, the net financial consequences for households, and the financial risk protection provided to households, that would be caused by a $50 \%$ increase in tobacco price through excise tax fully passed onto tobacco consumers. For our modelling analysis, we used plausible values for key

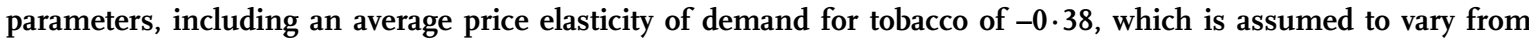
-0.64 in the poorest quintile to -0.12 in the richest, and we considered only the male population, which constitutes the overwhelming majority of smokers in China.

Findings Our modelling analysis showed that a $50 \%$ increase in tobacco price through excise tax would lead to 231 million years of life gained (95\% uncertainty range 194-268 million) over 50 years (a third of which would be gained in the lowest income quintile), a gain of US\$703 billion (\$616-781 billion) of additional tax revenues from the excise tax (14\% of which would come from the lowest income quintile, compared with $24 \%$ from the highest income quintile). The excise tax would increase overall household expenditures on tobacco by $\$ 376$ billion (\$232-505 billion), but decrease these expenditures by $\$ 21$ billion ( $\$ 83$ to $\$ 5$ billion) in the lowest income quintile, and would reduce expenditures on tobacco-related disease by $\$ 24.0$ billion $(\$ 17 \cdot 3-26.3$ billion, $28 \%$ of which would benefit the lowest income quintile). Finally, it would provide financial risk protection worth $\$ 1 \cdot 8$ billion (\$1.2-2.3 billion), mainly concentrated $(74 \%)$ in the lowest income quintile.

Interpretation Increased tobacco taxation can be a pro-poor policy instrument that brings substantial health and financial benefits to households in China.

Funding Bill \& Melinda Gates Foundation and Dalla Lana School of Public Health.

Copyright (C) Verguet et al. Open access article distributed under the terms of CC BY-NC-SA.

\section{Introduction}

Many low-income and middle-income countries, such as China, have undergone an epidemiological transition from communicable to non-communicable diseases in recent years, which imposes a growing economic burden on these nations. ${ }^{1,2}$ Tobacco use is a leading modifiable risk factor for non-communicable diseases, and in 2010 there were an estimated 5 million premature deaths attributable to smoking worldwide. ${ }^{3}$ Asia has the highest number of tobacco users and is the prime target of tobacco companies. ${ }^{4,5}$ Health behavioural changes have accelerated rapidly in China, including increasingly higher numbers of cigarettes smoked in the already very large male smoker population. ${ }^{6}$ Furthermore, the prevalence of smoking in women is still relatively low. ${ }^{7}$ In 2010, 1 million premature deaths were attributable to smoking in China, and the three leading causes of death (stroke, ischaemic heart disease, and chronic obstructive pulmonary disease) were linked to tobacco consumption. ${ }^{8,9}$

Tobacco taxation is widely recognised as very effective at reducing smoking, its attributable morbidity and mortality, ${ }^{10}$ and subsequently the burden of non-communicable diseases. ${ }^{3,11}$ Additionally, it provides revenues and potential for redistributive health financing. ${ }^{4,12,13}$ Tax comprises about two-thirds of the retail price of cigarettes in most high-income countries but less than half of the total price in most low-income and middle-income countries such as China, which indicates that there is potential room for taxation as a fiscal and health policy instrument. ${ }^{10,12,14-18}$

Although tobacco taxation is a cornerstone of the WHO Framework Convention on Tobacco Control, ${ }^{19}$ which was ratified by China in 2005, some controversy exists because

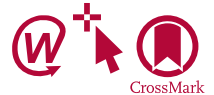

Lancet Glob Health 2015; 3: e206-16

Published Online March 13, 2015 http://dx.doi.org/10.1016/ S2214-109X(15)70095-1

See Editorial page e17

See Comment page e181

Department of Global Health and Population, Harvard T.H. Chan School of Public Health, Boston, MA, USA (S Verguet PhD); Department of Global Health, University of Washington, Seattle, WA, USA (S M Murphy MA, ED Brouwer MPH, R A Nugent PhD); Centre for Global Health Research, St Michael's Hospital, University of Toronto, Toronto, ON, Canada (C L Gauvreau PhD, S Mishra MA

M MacLennan MSC Prof P Jha DPhil); China National Health Development Research Center, Beijing, China (K Zhao MD); and Global Health Sciences, University of California, San Francisco, CA USA (Prof DT Jamison PhD)

Correspondence to: Dr Stéphane Verguet, Department of Global Health and Population, Harvard T.H. Chan School of Public Health,

665 Huntington Avenue, Boston MA 02115, USA verguet@hsph.harvard.edu 
Research in context

\section{Evidence before this study}

We did a search of PubMed using the search terms "China", "tobacco", "taxation", "impact", "socio-economic", "economic evaluation", "modeling", "income inequality", "youth", and "demand" in various combinations. We did not use any language or date restrictions. We did the same search on Google Scholar. We searched resources from relevant websites, especially from WHO and the International Agency for Research on Cancer. We also consulted with experts in the specialty.

Tobacco smoking is responsible for 5 million premature deaths worldwide. China has the highest number of tobacco users (>300 million) and is a prime target of tobacco companies. The deleterious health and economic consequences of smoking have been increasingly assessed and include modelling studies to identify suitable interventions. Tobacco taxation is widely recognised to be very effective at reducing tobacco use and initiation, and it provides financial revenues and potential for redistributive health financing. Tax comprises about two-thirds of the retail price of cigarettes in most high-income countries but less than half of the price in China, which indicates that there is potential room for taxation as a fiscal and health policy instrument. Few studies have assessed the distributional consequences of increased excise tobacco taxes in Asian economies, although the health and economic benefits of such a policy could be substantial.

\section{Added value of this study}

In this study, we used a unified analytical framework of extended cost-effectiveness analysis (ECEA) that models the distributional consequences (across income quintiles) in China of an increase in tobacco price of $50 \%$ through excise tax in terms of the health benefits (premature deaths averted), the additional tax revenues raised from excise tax, the net financial consequences for households, and the financial risk protection provided to households. We estimate substantial health gains, and find that reductions would occur in expenditures on tobacco-related disease, and financial risk protection from higher tobacco taxation; these benefits would disproportionally favour the lower-income population quintiles. We conclude that higher tobacco taxation can be a pro-poor policy device that brings substantial health and financial benefits to households in China.

\section{Implications of all the available evidence}

Higher tobacco taxes in China can reduce a substantial proportion of the global burden of smoking-related morbidity and mortality. Since tobacco use is a strong risk factor for many non-communicable diseases, for which health policy is still formulating in low-income and middleincome countries, large and immediate tax increases could have far-reaching health benefits, lower health care costs, and reduced disparities in health and economic outcomes, especially for the poorest populations. The estimation of financial risk protection of tobacco control policy is an especially fertile topic for further studies when considered in conjunction with the movement towards universal healthcare coverage, which is gathering strong momentum in many countries. of the potential regressivity of excise taxes such as those for tobacco. This regressivity is caused by the fact that poor people already spend a larger proportion of their income on smoking than do their wealthy counterparts, and taxes paid by the poor would constitute a larger proportion of their income than that of the rich, ${ }^{20}$ which is a source of concern to policy makers..$^{21}$ Although a given tobacco tax could be viewed as progressive depending on the specific methods used to assess the tax burden and the data source used, ${ }^{22}$ most researchers conclude that tobacco taxes exert a negative distributional effect. However, poor people are substantially more responsive to price changes than are their wealthy counterparts, which means that their consumption and tax burden could be lower, ${ }^{21,23-25}$ and therefore policy might reduce regressivity.

The effect of tobacco taxation should also be considered alongside the fact that tobacco and tobacco-related disease expenditures exacerbate the effects of poverty. Excessive medical spending attributable to smoking and consumption spending on cigarettes combined were estimated to impoverish 55 million Chinese people in the late $1990 \mathrm{~s} .{ }^{26}$ Smoking could also contribute to cycles of impoverishment if expenditures on education are displaced by those on smoking. ${ }^{27-30}$
In 2009, China launched a US\$125 billion 3-year health reform plan, the goals of which included achievement of universal health coverage and prevention of medical impoverishment. ${ }^{31}$ Since then, impressive progress has been made in provision of health insurance coverage, resulting in narrowing of the health care access gap between poorer and richer individuals. However, in one important area-financial risk protection—advances still need to be made because insurance covers only about $50 \%$ of inpatient costs and $30-40 \%$ of outpatient costs. ${ }^{31,32}$ In 2011, the poorest quartile of households in China had about twice as much catastrophic expenditure on health as those in the wealthiest quartile. ${ }^{33}$

Little work has studied the distributional consequences of increased tobacco taxation, although the health and economic benefits of such a policy could be substantial in Asian economies. ${ }^{4}$ Previous studies have assessed the policy outcomes including health benefits, health-care costs, regressivity, and financial risk protection separately and with different analytical devices. Here, we use the analytical method of extended cost-effectiveness analysis (ECEA) $)^{34}$ that can provide insights into these questions simultaneously in a unified model. We apply ECEA ${ }^{34-36}$ to a hypothetical excise tax that would raise the retail price 
of cigarettes by $50 \%$ in China. In the Chinese male smoking population, we estimate the distributional consequences (across income quintiles) of this hypothetical excise tax in terms of: health benefits (years of life gained); additional tax revenues raised from the excise tax; net change in expenditures on both tobacco products and tobacco-related disease (eg, stroke) treatment; and the financial risk protection provided to households by avoiding impoverishing health-care expenditures.

\section{Methods \\ Model}

Our modelling approach draws substantially from the Asian Development Bank's framework ${ }^{4}$ that estimates the effect of taxation-created cigarette price shocks. It accounts for price responsiveness across age and socioeconomic groups to compare the tax burden and health gains in each stratum based on existing and projected numbers of future smokers. ${ }^{4}$ Since Chinese men comprise the vast majority $(96 \%)$ of smokers in the country $(53 \%$ of men are smokers vs $2 \%$ of women ${ }^{37}$ ), this study focuses solely on the male population, which we model for 50 years. The population is replenished as older individuals die. The population is divided into five age groups of smokers: those younger than 15 years of age (representing potential future smokers); 15-24-year-olds; 25-44-year-olds; 45-64-yearolds; and those older than 65 years. These groups are further divided into income quintiles. Specifically, these quintiles were defined from four income cutoff values dividing the population into five groups (table 1).

We simulate a one-time excise tax fully passed onto consumers that results in the retail price of a pack of cigarettes increasing by $50 \%$. We use a pre-increase tax rate $(41 \%$ or US $\$ 0 \cdot 30)$ and cigarette pack price (US $\$ 0 \cdot 74$ ) extracted from MPOWER 2011, ${ }^{39}$ to capture an average tax and price per pack purchased. Many different cigarette brands with a wide price range are available in China. ${ }^{15,56-58}$ Hence, any tax increase will only benefit poor people if designed to reduce the so-called switching down effect to cheaper cigarette brands., ${ }^{3,410}$

The introduction of the excise tax has five main consequences: it reduces the number of premature deaths and associated years of life lost because of tobacco through induced smoking cessation; it brings excise tax revenues as tobacco price increases and cigarette consumption changes; it affects the household expenditures on tobacco depending on the tobacco price increase and cigarette consumption changes; it decreases expenditures on the treatment of tobacco-related disease as a consequence of the reduction in tobacco-related disease burden; and it brings financial risk protection to households by preventing medical expenditures related to the treatment of tobacco-related disease.

First, we estimate the years of life gained as a consequence of the price increase, solely among those who quit. We assume no health benefits would arise from reduced consumption caused by price changes among continuing smokers. Upon quitting, smokers gain a particular number of years of life, depending on their age

\begin{tabular}{lll}
\hline \multicolumn{2}{c}{ Value } & Data source \\
\hline $\begin{array}{l}\text { Size of male population in } \\
\text { China }\end{array}$ & 677 million & UN data, ${ }^{38}$ authors' assumptions \\
Age group (years) & & UN data $^{38}$ \\
$<15$ & $18 \%$ & \\
$15-24$ & $17 \%$ & \\
$25-44$ & $33 \%$ & \\
$45-64$ & $24 \%$ & \\
$\geq 65$ & $8 \%$ & \\
\hline
\end{tabular}

Smoking prevalence per age

Asian Development Bank ${ }^{4}$ and $\mathrm{WHO}^{37}$

group (\%)

$\begin{array}{ll}15-24 & 34 \% \\ 25-44 & 59 \% \\ 45-64 & 63 \% \\ \geq 65 & 40 \%\end{array}$

Relative smoking prevalence

per income quintile

Income quintiles 1-4 1.14-times average per age group

Income quintile 5 (richest) $\quad 0.86$-times average per age group

Cigarette consumption

(cigarettes per day) per

income quintile

$\begin{array}{ll}\text { Income quintile 1 (poorest) } & 15.6 \\ \text { Income quintile 2 } & 15 \cdot 5 \\ \text { Income quintile 3 } & 13.8 \\ \text { Income quintile 4 } & 12.7 \\ \text { Income quintile 5 (richest) } & 12.7\end{array}$

Price per pack of 20 cigarettes $\$ 0 \cdot 74$ (before excise tax increase), Asian Development Bank ${ }^{4}$ and WHO ${ }^{39}$ (2011 US\$)

$\$ 1.11$ (after excise tax increase)

Price elasticity of demand for

cigarette per income group

Distribution of tobacco-

related disease mortality, by

Authors' assumptions based on education levels in references ${ }^{4,37}$

cause (\%)

$\begin{array}{ll}\begin{array}{l}\text { Chronic obstructive } \\ \text { pulmonary disease }\end{array} & 11 \% \\ \text { Stroke } & 46 \% \\ \text { Heart disease } & 23 \% \\ \text { Neoplasm } & 20 \%\end{array}$

Years of life gained upon

tobacco cessation, per age

group

15-24year-olds

10 years

25-44 year-olds 9years

45-64year-olds 6years

$\geq 65$ year-olds 3years

Tobacco-related disease

treatment costs (2011 US\$)

Chronic obstructive

pulmonary disease

Stroke

See table 3

Authors' assumptions based on education levels in references ${ }^{4.37}$

Heart disease

Neoplasm

(Table 1 continues on next page) 


\begin{tabular}{|c|c|c|}
\hline \multicolumn{2}{|r|}{ Value } & Data source \\
\hline \multicolumn{3}{|l|}{ (Continued from previous page) } \\
\hline $\begin{array}{l}\text { Use of health care by } \\
\text { tobacco-related disease (\%) }\end{array}$ & & $\begin{array}{l}\text { Based on several studies } s^{5-53} \text { and } \\
\text { authors' assumptions }\end{array}$ \\
\hline $\begin{array}{l}\text { Chronic obstructive } \\
\text { pulmonary disease }\end{array}$ & $33 \%$ & \\
\hline Stroke & $80 \%$ & \\
\hline Heart disease & $81 \%$ & \\
\hline Neoplasm & $50 \%$ & \\
\hline $\begin{array}{l}\text { Relative use of health care per } \\
\text { income quintile }\end{array}$ & & $\begin{array}{l}\text { Authors' assumptions based on } \\
\text { reference }{ }^{54}\end{array}$ \\
\hline Income quintile 1 (poorest) & 0.79-times average & \\
\hline Income quintile 2 & 0.98 -times averages & \\
\hline Income quintile 3 & 1.00-times average & \\
\hline Income quintile 4 & 1.08-times average & \\
\hline Income quintile 5 (richest) & 1.15-times average & \\
\hline $\begin{array}{l}\text { Fraction of health care costs } \\
\text { reimbursed by insurance } \\
\text { schemes (\%) }\end{array}$ & $50 \%$ & $\begin{array}{l}\text { Authors' assumptions based on Yip } \\
\text { et a }{ }^{\beta^{1}}\end{array}$ \\
\hline $\begin{array}{l}\text { Individual annual income } \\
\text { (2011 US\$) }\end{array}$ & & $\begin{array}{l}\text { Income distribution based on gross } \\
\text { national income per person of } \$ 4940 \\
\text { and Gini coefficient of } 0 \cdot 42^{42,55}\end{array}$ \\
\hline Income quintile 1 (poorest) & $<\$ 1652$ & \\
\hline Income quintile 2 & $\$ 1652-3075$ & \\
\hline Income quintile 3 & $\$ 3075-4850$ & \\
\hline Income quintile 4 & $\$ 4850-7645$ & \\
\hline Income quintile 5 (richest) & $>\$ 7645$ & \\
\hline
\end{tabular}

*Note that although many neoplasms are affected by smoking (eg, oesophageal, mouth, trachea, bronchial, and lung cancers), for simplicity, we associate here neoplasm treatment cost with lung cancer treatment cost because of the significance of lung cancers among neoplasms affected by smoking and data availability.

Table 1: Inputs used in the modelling for the tobacco excise tax increase ( $50 \%$ retail price increase) in China

\begin{tabular}{|lcccccc|}
\hline & Total & $\begin{array}{l}\text { Income } \\
\text { quintile 1 }\end{array}$ & $\begin{array}{l}\text { Income } \\
\text { quintile 2 }\end{array}$ & $\begin{array}{l}\text { Income } \\
\text { quintile 3 }\end{array}$ & $\begin{array}{l}\text { Income } \\
\text { quintile 4 }\end{array}$ & $\begin{array}{l}\text { Income } \\
\text { quintile 5 }\end{array}$ \\
\hline$\geq 65$-year-olds & 24 & 5 & 5 & 5 & 5 & 4 \\
45-64-year-olds & 97 & 20 & 20 & 20 & 20 & 17 \\
25 -44-year-olds & 142 & 30 & 30 & 30 & 30 & 22 \\
15-24-year-olds & 43 & 9 & 9 & 9 & 9 & 7 \\
Future smokers (ie, <15-year-olds) & 43 & 9 & 9 & 9 & 9 & 7 \\
\hline $\begin{array}{l}\text { Table 2: Assumed number of smokers (in millions) by age group and income quintile, before excise tax } \\
\text { increase }\end{array}$ &
\end{tabular}

\begin{tabular}{|c|c|c|c|c|c|c|}
\hline & Average & $\begin{array}{l}\text { Income } \\
\text { quintile 1 }\end{array}$ & $\begin{array}{l}\text { Income } \\
\text { quintile } 2\end{array}$ & $\begin{array}{l}\text { Income } \\
\text { quintile } 3\end{array}$ & $\begin{array}{l}\text { Income } \\
\text { quintile } 4\end{array}$ & $\begin{array}{l}\text { Income } \\
\text { quintile } 5\end{array}$ \\
\hline$\geq 65$-year-olds & -0.38 & -0.64 & -0.51 & -0.38 & -0.25 & -0.12 \\
\hline 45-64-year-olds & -0.38 & -0.64 & -0.51 & -0.38 & -0.25 & -0.12 \\
\hline 25-44-year-olds & -0.38 & -0.64 & -0.51 & -0.38 & -0.25 & -0.12 \\
\hline 15-24-year-olds & -0.76 & $-1 \cdot 28$ & -1.02 & -0.76 & -0.50 & -0.24 \\
\hline Future smokers (ie, <15-year-olds) & -0.76 & $-1 \cdot 28$ & -1.02 & -0.76 & -0.50 & -0.24 \\
\hline
\end{tabular}

at cessation. ${ }^{40}$ We express years of life gained as a function of age $a$ at cessation. At present, China's mean male life expectancy is 71 years, ${ }^{59}$ and the number of years of life gained is assumed to be realised 71- $a$ after cessation. The number of quitters at age $a$ is related to the participation elasticity, which is assumed to be half of the total price elasticity of demand for tobacco. In other words, we assume that half of price increases affects smoking rates (participation elasticity), and the other half affects the consumption of non-quitters. This proportion is consistently represented in findings and assumptions from studies over 25 years. . $^{10,25,60,61}$ The total price elasticity (hereafter referred to as the price elasticity) refers to the change in number of cigarettes purchased by a population when price changes, owing to both outright quitting and reduced consumption of cigarettes. The change in smoking-related premature mortality is the product of the change in price increase, the price elasticity, the net effect of half this price change on smoking prevalence, and the life-years gained in those who quit depending on their age at quitting. The future smoking prevalence of those currently younger than 15 years of age is assumed to be the current prevalence rate for those aged $15-24$ years. The model assumes that no additional smoking initiation occurs in those aged 15 years and older. This approach is conservative because the prevalence for those 15-24 years old is likely to rise in view of the peak for those aged 25-44 years. $^{62}$ Additionally, we assume that the price elasticity is twice as large in young populations (15-24-yearolds and future smokers [ie, those $<15$ years old]) than in older smokers. ${ }^{410,61}$ Young smokers are generally believed to be more price responsive than older smokers because compared with older smokers they have less disposable income, lower addiction levels, and are more responsive to peer pressure. ${ }^{63,64}$ Recent reviews ${ }^{10,61}$ assessing tobacco use in youths showed that they can be two to three times more responsive to price than older people, with estimated price elasticities between -0.50 and -1.20 (where -0.5 and -1.20 equal a $0.5 \%$ and $1.20 \%$ fall in demand for every $1 \%$ increase in price) in most high-income countries. Although little research has been done on youth smoking in low-income and middle-income countries, similar conclusions generally apply. ${ }^{10}$ As a case in point, results from the Global Youth Tobacco Survey ${ }^{65}$ suggest that the price elasticity might be $-1 \cdot 8^{66}$ or even $-2 \cdot 2 .{ }^{67}$

Second, we estimate the additional tax revenues raised from the excise tax. The annual change is related to the change in cigarette consumption (which in turn is related to price elasticity), the change in excise taxes per pack (from US\$0.30 to $\$ 0.67$ here), and the number of smokers in a particular age group. Similarly, we estimate the net change in expenditures on tobacco, related to price elasticity, the change of price per pack (from $\$ 0.74$ to $\$ 1 \cdot 11)$, and the number of smokers in a given age group.

Third, we estimate the net change in expenditures on treatment of tobacco-related disease, following the reduced number of tobacco-related premature deaths. 
The number of premature deaths averted is estimated on the basis of the assumption that about $50 \%$ of smokers die of smoking-related illness and that this risk is reduced upon quitting by $97 \%$ in 15-24-year-olds, $85 \%$ in 25-44-year-olds, 75\% in 45-64-year-olds, and 25\% in those older than 65 years. ${ }^{4,40,41}$ The Global Burden of Disease Study 2010 classifies deaths caused by tobacco smoking as a risk factor among 20 possible disease outcomes (appendix), ${ }^{68}$ which are aggregated into the following four largest tobacco-related causes of death in China: stroke, ischaemic heart disease, chronic obstructive pulmonary disease, and neoplasms. ' Subsequently, we attribute the share of the premature deaths averted from these four causes. Based on these causes, and accounting for the proportion of people who will seek formal health-care treatment (health-care use), we assign treatment-related costs, to which we deduce the share reimbursed by insurance. Although many neoplasms are affected by smoking (eg, oesophageal, mouth, trachea, bronchus, and lung cancers), for simplicity, we associate neoplasm treatment cost with lung cancer treatment cost due to the significance of lung cancers in neoplasms affected by smoking and data availability.

Finally, we quantify the financial risk protection provided to the households related to the reduction in the risk of expenditures on the treatment of tobacco-related disease. We use a money-metric value of insurance as our financial risk protection metric, which has been described elsewhere ${ }^{34}$ and is detailed in the appendix. The results are then aggregated by income quintile. Complete details of the model are given in the appendix. We used $R$ statistical software (R 3.1.0) for all statistical analyses.

\section{Model parameters}

Tables 1-3 present all model key inputs. When relevant and where available data allow, parameter values vary by income quintile. For example, smoking prevalence and intensity (cigarettes per day) increase marginally as income quintile decreases. ${ }^{4,37}$ For simplicity and in view of the difficulty in extrapolating outcomes for the future in rapidly evolving China, we assume no price increases and no changes in household incomes and socioeconomic status over time after the one-time tobacco price increase.

One key driver of the analysis is the price elasticity by income quintile. Estimated Chinese price elasticities range from $-0 \cdot 01$ to $-0 \cdot 84^{15,58,69-76}$ owing to variations in datasets and estimation methods, and as reviewed by $\mathrm{Hu}$ and colleagues ${ }^{15,58}$ can be classified into: high-end elasticities (around $-0 \cdot 80$ ) as obtained from two time series and often cited for developing countries; ${ }^{10,61}$ middlerange elasticities (between -0.50 and -0.60 ), as estimated in half of studies and often cited for middleincome and high-income countries; ${ }^{10,61}$ and low-end elasticities (lower than $-0 \cdot 15$ ), as estimated from recent studies. ${ }^{15,58}$ The latter elasticities could be explained by the wide price variation (more than ten-fold) across cigarettes, which enables smokers to switch to cheaper

\begin{tabular}{|c|c|c|c|c|c|c|}
\hline & Total & $\begin{array}{l}\text { Income } \\
\text { quintile } 1\end{array}$ & $\begin{array}{l}\text { Income } \\
\text { quintile } 2\end{array}$ & $\begin{array}{l}\text { Income } \\
\text { quintile } 3\end{array}$ & $\begin{array}{l}\text { Income } \\
\text { quintile } 4\end{array}$ & $\begin{array}{l}\text { Income } \\
\text { quintile } 5\end{array}$ \\
\hline $\begin{array}{l}\text { Years of life gained } \\
\text { (millions) }\end{array}$ & $\begin{array}{l}231 \\
(194-268)\end{array}$ & $\begin{array}{l}79 \\
\text { (61 to } 96)\end{array}$ & $\begin{array}{c}63 \\
(45 \text { to } 80)\end{array}$ & $\begin{array}{c}47 \\
(30-65)\end{array}$ & $\begin{array}{l}31 \\
(16-51)\end{array}$ & $\begin{array}{c}11 \\
(2-27)\end{array}$ \\
\hline \multicolumn{7}{|c|}{ Additional tax revenues raised from excise tax } \\
\hline 2011 US\$ billion & $\begin{array}{l}703 \\
(616-781)\end{array}$ & $\begin{array}{l}98 \\
\text { (60 to } 142)\end{array}$ & $\begin{array}{l}134 \\
\text { (93 to 175) }\end{array}$ & $\begin{array}{l}152 \\
(114-187)\end{array}$ & $\begin{array}{l}170 \\
(134-200)\end{array}$ & $\begin{array}{l}149 \\
(119-167)\end{array}$ \\
\hline$\%$ of individual income & .. & $3 \cdot 87 \%$ & $2 \cdot 10 \%$ & $1.43 \%$ & $1.03 \%$ & $0.65 \%$ \\
\hline \multicolumn{7}{|c|}{ Change in expenditures on tobacco } \\
\hline 2011 US\$ billion & $\begin{array}{l}376 \\
(232-505)\end{array}$ & $\begin{array}{l}-21^{*} \\
\text { (-83 to } 52)\end{array}$ & $\begin{array}{l}40 \\
(-27 \text { to } 107)\end{array}$ & $\begin{array}{l}89 \\
(27-147)\end{array}$ & $\begin{array}{l}132 \\
(73-182)\end{array}$ & $\begin{array}{l}135 \\
(86-164)\end{array}$ \\
\hline$\%$ of individual income & .. & $-0.82 \%$ & $0.63 \%$ & $0.84 \%$ & $0.80 \%$ & $0.59 \%$ \\
\hline \multicolumn{7}{|c|}{ Expenditures on tobacco-related disease treatment averted } \\
\hline 2011 US\$ billion & $\begin{array}{l}24 \cdot 0 \\
(17 \cdot 3-26 \cdot 3)\end{array}$ & $\begin{array}{c}6.6 \\
(4.9 \text { to } 8 \cdot 6)\end{array}$ & $\begin{array}{c}6.9 \\
\text { (3.9 to } 7.5)\end{array}$ & $\begin{array}{c}5 \cdot 3 \\
(2 \cdot 7-6 \cdot 1)\end{array}$ & $\begin{array}{c}3 \cdot 7 \\
(1 \cdot 7-5 \cdot 9)\end{array}$ & $\begin{array}{c}1 \cdot 5 \\
(0 \cdot 3-3 \cdot 3)\end{array}$ \\
\hline$\%$ of individual income & .. & $0.26 \%$ & $0 \cdot 11 \%$ & $0.05 \%$ & $0.02 \%$ & $<0.01 \%$ \\
\hline $\begin{array}{l}\text { Financial risk protection } \\
\text { afforded }^{\dagger} \\
\text { (2011 US\$ billion) }\end{array}$ & $\begin{array}{c}1 \cdot 8 \\
(1 \cdot 2-2 \cdot 3)\end{array}$ & $\begin{array}{c}1 \cdot 3 \\
(0 \cdot 8-1 \cdot 8)\end{array}$ & $\begin{array}{c}0.3 \\
(0.1 \text { to } 0.4)\end{array}$ & $\begin{array}{c}0.1 \\
(0.06-0.2)\end{array}$ & $\begin{array}{c}0.1 \\
(0.02-0.1)\end{array}$ & $\begin{array}{l}<0.1 \\
(0.00-0.03)\end{array}$ \\
\hline
\end{tabular}

$95 \%$ uncertainty ranges are indicated in parentheses. *A negative value implies expenditures on tobacco averted. † Measured by a money-metric value of insurance.

Table 4: Cumulative results for the tobacco excise tax increase ( $50 \%$ retail price increase) in China, after 50 years

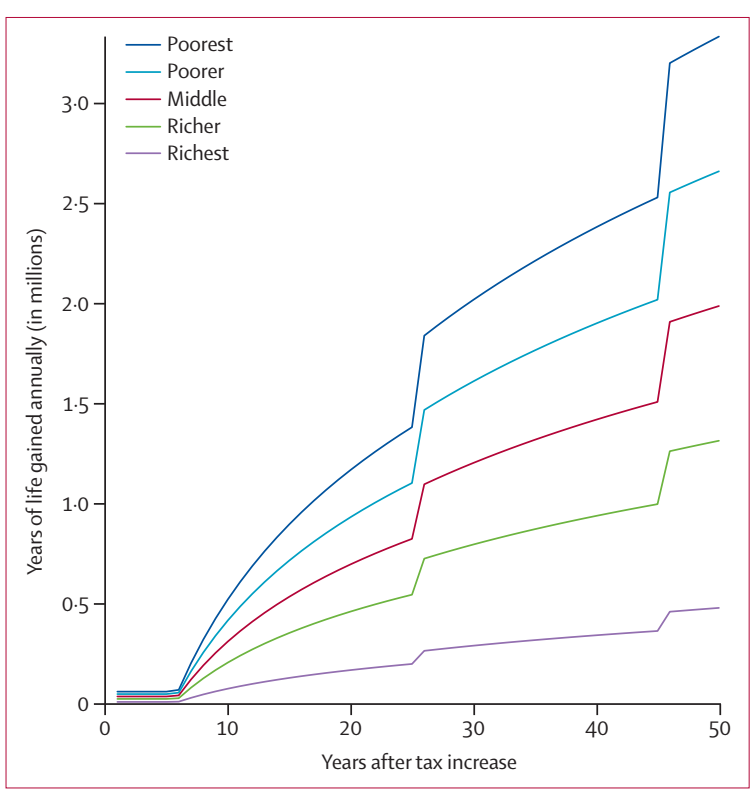

See Online for appendix

For R statistical software see www.r-project.org
Figure 1: Annual years of life gained for the tobacco excise tax increase ( $50 \%$ retail price increase) in China, over 50 years, by income quintile

cigarettes without quitting, and the rising affordability of cigarettes concomitant to the rapidly growing economy. ${ }^{15,56,58}$ In our analysis, we use -0.38 as our price elasticity, which corresponds to the mean elasticity from all studies reviewed by $\mathrm{Hu}$ and colleagues. ${ }^{15,58}$ In general, poorer populations, whether within a country or between countries, have higher price elasticities than do wealthier ones. ${ }^{10}$ We assume that the poorest income quintile is the most price elastic; the other quintiles are progressively less price elastic (based on data from $\mathrm{Hu}$ and colleagues ${ }^{58}$ ). 


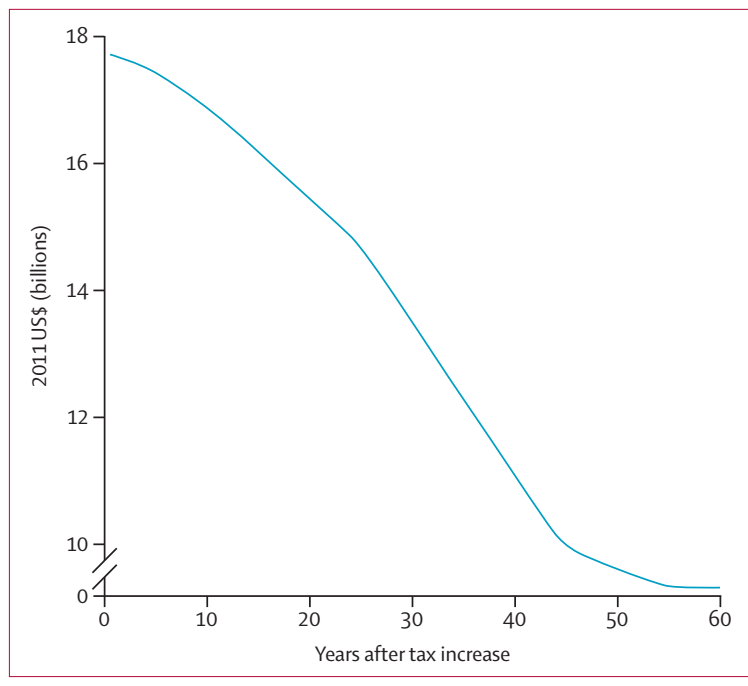

Figure 2: Additional tax revenues raised by the tobacco excise tax increase ( $50 \%$ retail price increase) in China, annually, over 60 years

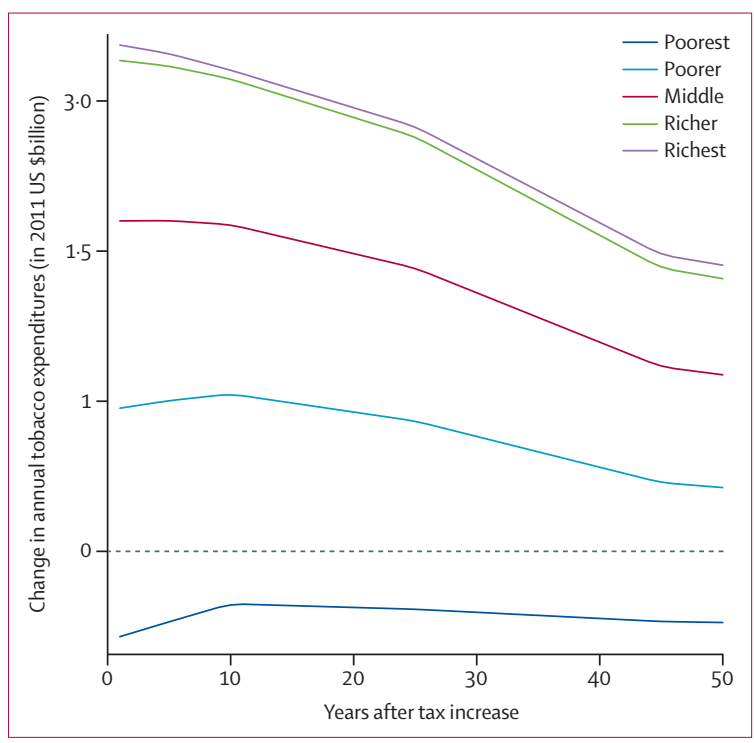

Figure 3: Annual change in expenditures on tobacco, with the tobacco excise tax increase ( $50 \%$ retail price increase) in China, over 50 years, by income quintile A negative value suggests expenditures on tobacco averted.

\section{Sensitivity analysis}

To increase the robustness of our findings, we first did a multivariate sensitivity analysis, in which we simultaneously varied several key parameters (eg, price elasticity and treatment costs). For this purpose, we did Monte Carlo simulations ( $n=100000$ trials) to capture uncertainty in treatment costs, health-care use, and price elasticity of demand for tobacco inputs. Uncertainty was included by sampling $n$ values for each parameter to which we assigned a beta distribution (eg, price elasticity and use) or a gamma distribution (eg, cost; appendix p 9). Finally, in the $n$ samples, extraction of the $2 \cdot 5$ and 97.5 percentiles allowed $95 \%$ uncertainty ranges (URs) to be established.
Second, we did univariate sensitivity analyses. We varied the price elasticity and set it to -0.38 across all income quintiles. We also varied the increase in the retail price of a pack of cigarettes attributable to excise tax, and alternatively set it to $25 \%$ (price increase from $\$ 0 \cdot 74$ to $\$ 0 \cdot 92$ ) and $100 \%$ (from $\$ 0 \cdot 74$ to $\$ 1 \cdot 48$ ).

\section{Role of the funding source}

The funder of the study had no role in study design or data collection. SV and coauthors had full access to all the data in the study. SV and DTJ had final responsibility for the decision to submit for publication.

\section{Results}

After 50 years of a $50 \%$ tobacco price increase in China, 231 million years of life would be gained (95\% UR 194-268 million), of which 79 million (34\%) would accrue to the lowest income quintile (table 4). The additional tax revenues raised from excise tax would be US\$703 billion (95\% UR 616-781), \$98 billion (14\%) of which would be borne by the bottom income quintile, compared with $\$ 149$ billion (24\%) in the highest income quintile and 170 billion (21\%) in the second highest income quintile (table 4). Total expenditures on tobacco would increase by about $\$ 376$ billion (95\% UR 232-505); however, these expenditures would decrease by $\$ 21$ billion (95\% UR -83 to 52 ) in the bottom income quintile and would increase in the other four income quintiles, ranging from US\$40 billion (95\% UR -27 to 107) in the second income quintile to $\$ 135$ billion (86-164) in the fifth income quintile (table 4). The expenditures on treatment of tobacco-related disease would decrease by $\$ 24$ billion (95\% UR 17-26), \$6.6 billion (27\%) of which would be concentrated in the poorest quintile. The financial risk protection afforded would amount to about $\$ 1.8$ billion overall (95\% UR $1.2-2 \cdot 3)$ and would also be concentrated ( $\$ 1 \cdot 3$ billion [74\%]) in the poorest quintile (table 4). Short-term results (within 10 years) are also given in the appendix.

The annual health gains are increasing over time because the younger age groups (15-24-year-olds and future smokers) contribute more substantially to the years of life gained and face a higher price elasticity than do older smokers (figure 1). The annual additional tax revenues from excise tax decrease over time as younger age groups, who are more price elastic than older people, replace older age groups and account for the majority of the population. The annual additional revenues raised start at US\$17.7 billion per year (95\% UR 15.5-19.7) in year 1 , which accounts for about $15.9 \%$ of cigarette tax and industry profit and $1.2 \%$ of government revenue in China in $2011,{ }^{58,77,78}$ to eventually fall to $\$ 9.2$ billion $(8 \cdot 0-10 \cdot 3)$ in year 60 , which represents about $8 \cdot 3 \%$ of cigarette tax and industry profit and $0.6 \%$ of government revenue in China in $2011^{58,7,78}$ (figure 2). Finally, the annual change in expenditures on tobacco decrease over time as younger age groups, who are more price elastic 
than older people, replace older age groups and account for the majority of the population (figure 3 ).

The paid out additional excise taxes represent a larger share of income of the low-income quintiles $(3.9 \%$ and $2 \cdot 1 \%$ for the bottom and second lowest income quintiles, respectively), than of the higher income quintiles $(1.0 \%$ and $0.7 \%$ for the second highest and highest income quintiles, respectively; table 4). In terms of expenditures on tobacco, the lowest income quintile sees decreases in expenditures, representing $-0 \cdot 8 \%$ of their income, by contrast with the two highest income quintiles that see increases in expenditures on tobacco of $0.8 \%$ and $0.6 \%$ of their incomes, respectively (table 4). Similarly, expenditures on tobacco-related disease averted as a fraction of income are higher in the bottom two quintiles $(0.3 \%$ and $0.1 \%)$ than in the top two quintiles $(0.02 \%$ at most). Therefore, in our base case scenario, although increased tobacco excise tax represents a larger share of income of the lower income quintiles, its other effects are largely positive and benefit poor populations disproportionately.

By contrast, when price elasticity is held constant at -0.38 across all income groups, the distributional consequences change substantially, as would be expected (table 5). The health benefits are similar (47 million years of life gained) across all income quintiles apart from the fifth (35 million years of life gained), in view of the fact that smoking prevalence was assumed to be similar across the four quintiles, except for the fifth quintile (the richest quintile), which has a lower smoking prevalence than the other quintiles. Additionally, the bottom two income quintiles contribute to the additional tax revenues to a greater extent than the top two quintiles (table 5). Furthermore, expenditures on tobacco increase for all income groups, with larger increases in the bottom two quintiles than the top two quintiles (table 5). Finally, the expenditures on tobacco-related disease averted are evenly distributed across all income groups, between US\$4 and \$6 billion, although the financial risk protection afforded remains mainly concentrated in the poorest groups. In this latter scenario, tobacco taxation is more regressive, and the diminished benefits do not accrue as strongly to the lowest income groups, but nevertheless substantial financial risk protection is disproportionately achieved because of the decrease in tobacco-related health-care expenditures.

Finally, when retail price increase for a packet of cigarettes is set at $\$ 0.92$ (25\% price increase) or $\$ 1.48$ (100\% price increase), the distributional consequences for health benefits, expenditures on tobacco-related disease, and financial risk protection change only a little (although the overall changes are substantial). When cigarette packet retail price is $\$ 0 \cdot 92$, total health benefits are reduced to 115 million years of life gained, total expenditures on tobacco-related disease averted are reduced to $\$ 12 \cdot 1$ billion, and total financial risk protection provided to households falls to $\$ 0.9$ billion. When retail price is $\$ 1 \cdot 48$, total health benefits are increased to 462 million years of life gained,

\begin{tabular}{|c|c|c|c|c|c|c|}
\hline & Total & $\begin{array}{l}\text { Income } \\
\text { quintile } 1\end{array}$ & $\begin{array}{l}\text { Income } \\
\text { quintile } 2\end{array}$ & $\begin{array}{l}\text { Income } \\
\text { quintile } 3\end{array}$ & $\begin{array}{l}\text { Income } \\
\text { quintile } 4\end{array}$ & $\begin{array}{l}\text { Income } \\
\text { quintile } 5\end{array}$ \\
\hline \multicolumn{7}{|c|}{ Price elasticity is set at -0.38 across all income quintiles } \\
\hline Years of life gained (millions) & 223 & 47 & 47 & 47 & 47 & 35 \\
\hline \multicolumn{7}{|l|}{$\begin{array}{l}\text { Additional tax revenues raised } \\
\text { from excise tax }\end{array}$} \\
\hline 2011 US\$ billion & 736 & 171 & 170 & 152 & 139 & 104 \\
\hline$\%$ of individual income & .. & $6 \cdot 77 \%$ & $2 \cdot 67 \%$ & $1.43 \%$ & $0.84 \%$ & $0.45 \%$ \\
\hline \multicolumn{7}{|c|}{ Change in expenditures on tobacco } \\
\hline 2011 US\$ billion & 432 & 100 & 100 & 89 & 82 & 61 \\
\hline$\%$ of individual income & .. & $3.97 \%$ & $1.56 \%$ & $0.84 \%$ & $0.49 \%$ & $0.26 \%$ \\
\hline
\end{tabular}

Expenditures on tobacco-related

disease treatment averted

$\begin{array}{lclllll}\text { 2011 US\$ billion } & 24.9 & 4.1 & 5.2 & 5.3 & 5.7 & 4.6 \\ \text { \% of individual income } & . . & 0.16 \% & 0.08 \% & 0.05 \% & 0.03 \% & 0.02 \% \\ \text { Financial risk protection afforded* } & 1.3 & 0.8 & 0.2 & 0.1 & 0.1 & <0.1\end{array}$

(2011 US\$ billion)

Cigarette price is set at $\$ 0.92$ (retail price increase is set at $25 \%$ )

Years of life gained (millions)

$115 \quad 39 \quad 31$

Additional tax revenues raised

from excise tax

2011 US\$ billion

$\%$ of individual income$$
421
$$

Change in expenditures on tobacco

2011 US $\$$ billion

$\%$ of individual income

258

Expenditures on tobacco-related

disease treatment averted

$\begin{array}{lclllll}\text { 2011 US\$ billion } & 12.1 & 3.3 & 3.5 & 2.7 & 1.9 & 0.7 \\ \text { \% of individual income } & . . & 0.13 \% & 0.05 \% & 0.03 \% & 0.01 \% & <0.01 \% \\ \text { Financial risk protection } \text { afforded }^{*} & 0.9 & 0.7 & 0.1 & 0.1 & <0.1 & <0.1\end{array}$

Financial risk protection afforded*

$0.9 \quad 0.7$

0.1

Cigarette price is set at $\$ 1.48$ (increase in retail price is set at $100 \%$ )

Years of life gained (millions)

462

157

126

94

62

23

from excise tax

\section{US\$ billion \\ $\%$ of individual income}

851

$851-5 \dagger \quad 108$

198

Change in expenditures on tobacco

2011 US\$ billion

$\%$ of individual income

Expenditures on tobacco-related

disease treatment averted

2011 US\$ billion

$\%$ of individual income

Financial risk protection afforded* (2011 US\$ billion)
Three scenarios are assessed in this table: 1 ) price elasticity is set at -0.38 across all income quintiles (all other parameters remain identical as in the base case scenario); 2 ) increase in retail price of cigarettes is set at $25 \%$ (all other parameters remain identical as in the base case scenario, including price elasticity of demand for cigarette varying by income quintile); and 3) increase in retail price of cigarettes is set at 100\% (all other parameters remain identical as in the base case scenario, including price elasticity of demand for cigarette varying by income quintile). * Measured by a money-metric value of insurance. $\dagger A$ negative value implies that expenditures on tobacco were averted.

Table 5: Sensitivity analysis results (cumulative) for the tobacco excise tax increase (through retail price increase) in China after 50 years 
total expenditures on tobacco-related disease averted to $\$ 48.3$ billion, and total financial risk protection provided to $\$ 3.6$ billion. Nonetheless, we note variations for the additional revenues raised from excise tax and the net change in expenditures on tobacco. When the price of a cigarette pack is $\$ 0.92$, the distribution of additional tax revenues raised remains almost unchanged: the bottom quintile contributes more substantially (in terms of income) than the other quintiles; however, it now sees an increase in tobacco expenditures. When the price of a packet of cigarettes is $\$ 1 \cdot 48$, the distribution of additional tax revenues raised changes substantially: the lowest income quintile sees a decrease in excise taxes paid and a substantial decrease in tobacco expenditures; the second lowest income quintile also undergoes a decrease in tobacco expenditures. In the $100 \%$ price increase, tobacco taxation is especially progressive: all health and financial outcomes provide substantial benefit to the poorest groups.

\section{Discussion}

Tobacco tax hikes are essential in view of the increasing relative affordability of tobacco. ${ }^{79,80}$ Since China's economy has grown enormously, cigarettes have become cheaper to smokers, which means that more aggressive tobacco taxation is now needed.

This study assesses the distributional consequences on four policy-relevant outcomes of a $50 \%$ retail price hike on tobacco products in China. Through the use of plausible values for key parameters, we find that in a 50 -year period, in the male population, a $50 \%$ increase in tobacco price would lead to 231 million years of life gained (a third of these in the poorest group) and US $\$ 703$ billion of additional tax revenues from excise tax (14\% of this in the poorest group). It would increase overall household expenditures on tobacco by $\$ 376$ billion, but reduce these expenditures by $\$ 21$ billion in the poorest quintile; it would also decrease expenditures on tobacco-related disease by $\$ 24$ billion (28\% of which would be in the poorest group). Finally, it would provide financial risk protection worth US $\$ 1.8$ billion, mainly concentrated (74\%) in the poorest households. This situation means that tobacco taxation can be a pro-poor policy instrument that brings notable health and financial benefits to households and substantial revenues to society, which is especially important in the poor population of China, which has the highest number of smokers of any country worldwide.

We also show that it is important to comprehensively integrate distributional aspects into analyses. We found that important insights into the equity of tobacco taxation can be otherwise missed when, as is done conventionally, a constant rather than an income-group-specific price elasticity is used. In China, where major reforms in health care are being made with the aim of reducing inequalities, proper assessment of policy instruments might be difficult unless explicit recognition of the income-specific variation in tobacco demand and health-care use and expenditures are made. In particular, Chinese price variation is more than ten-fold across different brands of cigarettes $^{15,56,58}$ as opposed to only about two-fold in most high-income countries, ${ }^{3}$ which enables smokers to switch down with modest consumer tax increases. ${ }^{80}$ Specifically, an effective price increase in China would need substantial increases in excise tax on the cheaper cigarettes ${ }^{3,10}$ to narrow the large gap between cheap and more expensive cigarettes. The Indian Government, for example, has recently taken on cheaper cigarettes directly by raising the tax on lower end cigarettes more than that on more expensive brands. An important consideration is the weighing of taxation regressivity against the health benefits and financial risk protection resulting from reduced tobacco-related diseases in a consistent and similar framework such as here.

Our analysis has some limitations. First, uncertainty exists in the parameter inputs, of which the most important is the price elasticity of demand for tobacco. A wide range of elasticities has been estimated for China, and some studies have suggested that smokers in China could be quite insensitive to price changes compared with those in other countries. ${ }^{81}$ We chose a middle value among the range of values for China, and one that is close to the accepted value for most countries $(-0.4)$ and that would probably represent true price elasticities without the distortion of wide price variation that exists at present in China. ${ }^{10}$ The wide variations in price including five classes of cigarettes ${ }^{58}$ could change the brand selection of some smokers. Although we did not incorporate any such compensating behaviour (switching to lower price of cigarettes), as in $\mathrm{Hu}$ and colleagues' study, ${ }^{15}$ we ran a sensitivity analysis with a low elasticity of $-0 \cdot 15$, and noted that important health, additional excise tax revenues, and equity gains could still be realised (appendix p 11). Although value-added taxes as in China's tiered price system encourage smokers to switch down to cheaper cigarettes, specific excise taxes as studied here can be designed to narrow the gap between cheap and expensive cigarettes to prevent smokers from swapping to cheaper brands. ${ }^{15,58,80}$ Furthermore, we did a multivariate sensitivity analysis and our results were robust with the uncertainty imposed.

Second, we assumed that no health benefits would arise from reduced tobacco consumption because of a price hike among continuing smokers. Because we do not take into account the changes in the intensity of smoking, our estimates are therefore conservative. Similarly, we excluded female smokers from our analysis because they represent a small population (4\% of all Chinese smokers ${ }^{37}$ ), although women's behaviour and household situation might somewhat differ from that of men.

Third, our epidemiological model has some shortcomings. For example, the non-linear harm caused by smoking intensity is not modelled. ${ }^{82}$ Additionally, a more exhaustive dynamic model with, say, age-specific 
mortality with and without smoking would have yielded a more realistic and nuanced scenario, but simplicity of exposition, scarcity of data, and the benefits of transparency encouraged us to maintain our modelling approach. Furthermore, our results could have been discounted, treatment costs averted inflated using trends of the Chinese consumer price index, and individual incomes increased over the years with trends in the Chinese growth rate. ${ }^{42}$ These adjustments would have unnecessarily complicated the results without providing any additional insight. Our financial analysis does not incorporate the effects of inflation and growth in gross domestic product and household income, which would ultimately strongly affect the benefits of tax increases of a fixed size. Neither does our model take into account consequences on tobacco consumers' utility, which is in any case ambiguous because of an (often) simultaneous willingness to pay for tobacco and for aid in cessation. Moreover, our model could have taken the household disposable income or used consumption data to estimate standards of living, but because of data shortcomings, gross national income distributed in income quintiles based on China's Gini coefficient was used as a substitute income indicator. ${ }^{42,55}$ Likewise, we did not incorporate any perception of risks by individuals who smoke and the resulting effect on current consumption, or lagged consumption responses. Taxes could indeed serve as a self-control device to help reduce tobacco use and enable successful quitting.

Whether or not taxes are appropriately high depends in part on how excessively people underrate the harm from tobacco use. ${ }^{83-86}$ However, these issues are not well explored in China or other low-income and middleincome countries, and extrapolation from studies done in high-income countries was judged to be inadvisable. Our analysis only focused on additional tax revenues raised from excise tax and did not estimate net government revenues through taxation. Since our intent is to take the consumer perspective, we did not model the Chinese tobacco tax structure. Indeed, China's tobacco industry operates under a system of monopoly that is able not to tie tax increases to cigarette retail prices. ${ }^{16}$ Both a central government tax (eg, value-added tax) and a local government tax (eg, special tobacco leaf tax) are collected..$^{15,58}$ Hence, tobacco excise taxes will only have an effect when increases are passed onto the retail price. ${ }^{16,80}$

We show that it is possible and desirable to use the same framework to study distributional effects when a combination of outcomes related to different highpriority policy objectives need to be considered. This study shows that, despite potentially imposing a tax burden on low-income groups, tobacco taxation can bring substantial health benefits to poor people and can significantly reduce out-of-pocket expenditures for the poorest populations, especially as these lowest income groups are the most sensitive to increases in prices of tobacco products (panel). Increased tobacco taxation also brings significant financial risk protection to the poorest households through reductions in tobacco-related treatment expenditures.

More than 30 years ago the World Bank argued in support of Chinese government policies initiated in late 1981 to increase the retail price of cigarettes by $30 \%{ }^{87}$ The current analysis has concluded that such policies are pro-poor in their financial as well as health consequences.

\section{Contributors}

SV and DTJ initiated and conceptualised the study. SV coordinated the research and did the analysis with CLG, SM, MM, SMM, and EDB. SV wrote the first draft of the report. RAN, KZ, PJ, and DTJ reviewed the report and provided advice and suggestions. SV and DTJ had final responsibility for the decision to submit for publication.

\section{Declaration of interests}

We declare no competing interests.

\section{Acknowledgments}

We thank the Bill \& Melinda Gates Foundation for funding through the Disease Control Priorities Network grant to the University of Washington. We received valuable comments from Evan Blecher, Zachary Olson, Clint Pecenka, Nisreen Salti, Helen Saxenian, and Gillian Tarr. Finally, we would like to thank five anonymous reviewers for providing very valuable and constructive suggestions.

\section{References}

1 Bloom DE, Cafiero E, Jané-Llopis E, et al. The global economic burden of non-communicable diseases (no. 8712). Program on the Global Demography of Aging, 2012. http://ideas.repec.org/p/gdm/ wpaper/8712.html (accessed April 20, 2014).

2 Jha P, Nugent R, Verguet S, Bloom D, Hum R. Chronic disease control and prevention. In: Lomborg B, ed. Global problems, smart solutions - costs and benefits. Cambridge: Cambridge University Press, 2013.

3 Jha P, Peto R. Global effects of smoking, of quitting, and of taxing tobacco. N Engl J Med 2014; 370: 60-68.

4 Asian Development Bank. Tobacco taxes: a win-win measure for fiscal space and health. Manila: Asian Development Bank, 2012.

5 Mackay J, Ritthiphakdee B, Reddy KS. Tobacco control in Asia. Lancet 2013; 381: 1581-87.

6 Yang G, Kong L, Zhao W, et al. Emergence of chronic noncommunicable diseases in China. Lancet 2008; 372: 1697-705.

7 Ho MG, Ma S, Chai W, Xia W, Yang G, Novotny TE. Smoking among rural and urban young women in China. Tob Control 2010; 19: 13-18.

8 Yang G, Wang Y, Zeng Y, et al. Rapid health transition in China, 1990-2010: findings from the Global Burden of Disease Study 2010. Lancet 2013; 381: 1987-2015.

9 Global Burden of Disease Study 2010. Global Burden of Disease Study 2010. Results by risk factor 1990-2010. Seattle: Institute for Health Metrics and Evaluation, 2012.

10 International Agency for Research on Cancer, World Health Organization. IARC handbook of cancer prevention, volume 14: effectiveness of tax and price policies for tobacco control. Lyon: World Health Organization, 2011.

11 Jamison DT, Summers LH, Alleyne G, et al. Global health 2035: a world converging within a generation. Lancet 2013; 382: 1898-955.

12 Chaloupka FJ, Straif K, Leon ME. Effectiveness of tax and price policies in tobacco control. Tob Control 2011; 20: 235-38.

13 WHO. World Health Report 2010. Health systems financing: the path to universal coverage. Geneva: World Health Organization, 2010.

14 Jha P, Chaloupka FJ. Tobacco control in developing countries. New York: Oxford University Press, 2000.

15 Hu T-w, Mao Z, Shi J, Chen W. The role of taxation in tobacco control and its potential economic impact in China. Tob Control 2010; 19: 58-64.

16 Gao S, Zheng R, Hu T-w. Can increases in the cigarette tax rate be linked to cigarette retail prices? Solving mysteries related to the cigarette pricing mechanism in China. Tob Control 2012; 21: 560-62. 
17 Hu T-w. Tobacco control policy analysis in China: economics and health. Singapore: World Scientific Publishing Co, 2008.

18 Levy D, Rodríguez-Buño RL, Hu T-w, Moran AE. The potential effects of tobacco control in China: projections from the China SimSmoke simulation model. BMJ 2014; 348: g1134.

19 World Health Organization. World Health Organization Framework Convention on Tobacco Control. http://www.who.int/fctc/en/ (accessed Dec 9, 2013).

20 Stiglitz J. Economics of the public sector, 3rd edn. New York: WW Norton \& Co, 2000

21 Warner KE. The economics of tobacco: myths and realities. Tob Control 2000; 9: 78-89.

22 Remler DK. Poor smokers, poor quitters, and cigarette tax regressivity. Am J Public Health 2004; 94: 225-29.

23 Chaloupka FJ. Rational addictive behavior and cigarette smoking, National Bureau of Economic Research Working Paper No. 3268. National Bureau of Economic Research, 1991. http://www.nber.org/ papers/w3268 (accessed April 20, 2014).

24 Townsend J, Roderick P, Cooper J. Cigarette smoking by socioeconomic group, sex, and age: effects of price, income, and health publicity. BMJ 1994; 309: 923-27.

25 Farrelly MC, Bray JW. Response to increases in cigarette prices by race/ethnicity, income, and age groups-United States, 1976-1993. JAMA 1998; 280: 1979-80.

26 Liu Y, Rao K, Hu T-w, Sun Q, Mao Z. Cigarette smoking and poverty in China. Soc Sci Med 2006; 63: 2784-90.

27 Wang H, Sindelar JL, Busch SH. The impact of tobacco expenditure on household consumption patterns in rural China. Soc Sci Med 2006; 62: 1414-26.

28 Xin Y, Qian J, Xu L, Tang S, Gao J, Critchley JA. The impact of smoking and quitting on household expenditure patterns and medical care costs in China. Tob Control 2009; 18: 150-55.

29 John RM, Ross H, Blecher E. Tobacco expenditures and its implications for household resource allocation in Cambodia. Tob Control 2012; 21: 341-46.

30 Hu T-w, Mao Z, Liu Y, de Beyer J, Ong M. Smoking, standard of living, and poverty in China. Tob Control 2005; 14: 247-50.

31 Yip W, Hsiao WC, Chen W, Hu S, Ma J, Maynard A. Early appraisal of China's huge and complex health care reforms. Lancet 2012; 379: 833-42.

32 Yip W, Hsiao WC. Non-evidence-based policy: how effective is China's new cooperative medical scheme in reducing medica impoverishment. Soc Sci Med 2009; 68: 201-09.

33 Meng Q, Xu L, Zhang Y, et al. Trends in access to health services and financial protection in China between 2003 and 2011: a cross-sectional study. Lancet 2012; 379: 805-14.

34 Verguet S, Laxminarayan R, Jamison DT. Universal public finance of tuberculosis treatment in India: an extended cost-effectiveness analysis. Health Econ 2015; 24: 318-32.

35 Verguet S, Murphy S, Anderson B, et al. Public finance of rotavirus vaccination in India and Ethiopia: an extended cost-effectiveness analysis. Vaccine 2013; 31: 4902-10.

36 Verguet S, Olson ZD, Babigumira JB, et al. Assessing pathways to universal health coverage in Ethiopia: health gains and financial risk protection afforded from selected interventions. Lancet Global Health (in press).

37 World Health Organization. Global Adult Tobacco Survey (GATS) China 2010 Country Report. Geneva: World Health Organization, 2010. http://www.who.int/tobacco/surveillance/gats/en/ (accessed Dec 9, 2013).

38 United Nations, Department of Economic and Social Affairs, Population Division. http://www.un.org/en/development/desa/ population/publications/dataset/index.shtml (accessed Aug 13, 2013).

39 World Health Organization. MPOWER: a policy package to reverse the tobacco epidemic. Geneva: World Health Organization, 2011.

40 Doll R, Peto R, Boreham J, Sutherland I. Mortality in relation to smoking: 50 years' observations on male British doctors. BMJ 2004; 328: 1519.

41 Jha P, Chaloupka FJ, Moore J, et al. Tobacco addiction. In: Jamison DT, Breman JG, Measham AR, et al, eds. Disease control priorities in developing countries, 2nd edn. New York: Oxford University Press and the World Bank, 2006.
42 World Bank. World development indicators. http://data.worldbank. org/data-catalog/world-development-indicators (accessed Dec 9, 2013).

43 She J, Yang P, Hong Q, Bai C. Lung cancer in China: challenges and interventions. Chest 2013; 143: 1117-126.

44 Le C, Zhankun S, Jun D, Keying Z. The economic burden of hypertension in rural south-west China. Trop Med Int Health 2012; 17: 1544-51.

45 Lee VW, Chan WK, Lam NL, Lee KK. Cost of acute myocardial infarction in Hong Kong. Dis Manage Health Outcomes 2005; 13: 281-85.

46 Wei JW, Heeley EL, Jan S, et al. Variations and determinants of hospital costs for acute stroke in China. PLoS One 2010; 5: e13041.

47 Ma Y, Liu Y, Fu H, et al. Evaluation of admission characteristics, hospital length of stay and costs for cerebral infarction in a medium-sized city in China. Eur J Neurol 2010; 17: 1270-76.

48 Heeley E, Anderson CS, Huang Y, et al. Role of health insurance in averting economic hardship in families after acute stroke in China. Stroke 2009; 40: 2149-56.

49 He QY, Zhou X, Xie CM, Liang ZA, Chen P, Wu CG. Impact of chronic obstructive pulmonary disease on quality of life and economic burden in Chinese urban areas. Zhonghua Jie He He Hu Xi Za Zhi 2009; 32: 253-57.

50 Zeng X, Karnon J, Wang S, Wu B, Wan X, Peng L. The cost of treating advanced non-small cell lung cancer: estimates from the Chinese experience. PLoS One 2012; 7: e48323.

51 Zhong N, Wang C, Yao W, et al. Prevalence of chronic obstructive pulmonary disease in China: a large, population-based survey. Am J Respir Crit Care Med 2007; 176: 753-60.

52 Zhao D, Liu J, Wang W, et al. Epidemiological transition of stroke in China twenty-one-year observational study from the Sino-MONICABeijing project. Stroke 2008; 39: 1668-74.

53 Chai Y, Xu H, Wang W, et al. A survey of factors associated with the utilization of community health centers for managing hypertensive patients in Chengdu, China. PLoS One 2011; 6: e21718.

54 Shanghai Municipal Center for Disease Control \& Prevention (SCDC). Study on global AGEing and adult health (SAGE), Wave 1. China National Report. Study Report October, 2012. http://apps. who.int/healthinfo/systems/surveydata/index.php/catalog/13/ download/1874 (accessed April 23, 2014).

55 Salem ABZ, Mount TD. A convenient descriptive model of income distribution: the gamma density. Econometrica 1974; 42: 1115-27.

56 Chinese Center for Disease Control and Prevention. Global adult tobacco survey (GATS) China 2010 country report. http://www.who. int/tobacco/surveillance/survey/gats/en_gats_china_report.pdf (accessed Dec 29, 2014).

57 Shang C, Chaloupka FJ, Zahra N, Fong GT. The distribution of cigarette prices under different tax structures: findings from the International Tobacco Control Policy Evaluation (ITC) project. Tob Control 2013; DOI:10.1136/tobaccocontrol-2013-050966

58 Hu T-w, Mao Z, Shi J, Chen W. Tobacco taxation and its potential impact in China. Paris: International Union Against Tuberculosis and Lung Disease, 2008.

59 World Health Organization. Life tables. Global Health Observatory. http://www.who.int/gho/mortality_burden_disease/life_tables/life tables/en/ (accessed Dec 9, 2013).

60 Gallet CA, List JA. Cigarette demand: a meta-analysis of elasticities. Health Econ 2003; 12: 821-35.

61 World Health Organization. WHO technical manual on tobacco tax administration. Geneva: World Health Organization, 2010.

62 Jha P, Jacob B, Gajalakshmi V, et al. A nationally representative case-control study of smoking and death in India. $N$ Engl J Med 2008; 358: 1137-47.

63 Grossman M, Chaloupka FJ. Cigarette taxes, the straw to break the camel's back. Public Health Reports 1997; 112: 291-97.

64 Lewit EM, Coate D, Grossman M. The effects of government regulation on teenage smoking. J Law Econ 1981; 24: 545-49.

65 Global Youth Tobacco Survey Collaborative Group. Global Youth Tobacco Survey. http://www.who.int/tobacco/surveillance/gyts/en/ (accessed Dec 9, 2013).

66 Kostova D, Ross H, Blecher E, Markowitz S. Prices and cigarette demand: evidence from youth tobacco use in developing countries. National Bureau of Economic Research Working Paper no.15781. Cambridge, MA: National Bureau of Economic Research, 2010. 
67 Nikaj S, Chaloupka FJ. The effect of prices on cigarette use among youths in the Global Youth Tobacco Survey. Nicotine Tob Res 2013; published online May 24. DOI: 10.1093/ntr/ntt019.

68 Lim SS, Vos T, Flaxman AD, et al. A comparative risk assessment of burden of disease and injury attributable to 67 risk factors and risk factor clusters in 21 regions, 1990-2010: a systematic analysis for the Global Burden of Disease Study 2010. Lancet 2012; 380: 2224-60.

69 Mao ZZ, Jiang JL. Demand for cigarette and pricing policy [in Chinese]. Chinese Health Economics 1997; 16: 50-52.

$70 \mathrm{Hu}$ T-w, Mao ZZ. Effects of cigarette tax on cigarette consumption and the Chinese economy. Tob Control 2002; 11: 105-08.

71 Mao ZZ, Hu T-w, Yang GH. New estimate of the demand for cigarettes in China. Chin J Health Econ 2005; 24: 45-47 [in Chinese].

72 Bai Y, Zhang Z. Aggregate cigarette demand and regional differences in China. Appl Econ 2005; 37: 2523-28.

73 Mao ZZ, Jiang JL. Determinants of the demand for cigarettes: a cross-sectional study. Chin Health Service Management 1997; 13: 227-29 [in Chinese].

74 Mao ZX, Yang GH, Ma H. Adults' demand for cigarettes and its determinants in China. Soft Sci Health 2003; 17: 19-23 [in Chinese].

75 Mao ZZ, Hu T-w, Yang GH. Price elasticities and impact of tobacco tax among various income groups [in Chinese]. Chin J Evidence-Based Med 2005; 5: 291-95.

76 Kostova D, Chaloupka FJ, Yurekli A, et al. A cross-country study of cigarette prices and affordability: evidence from the Global Adult Tobacco Survey. Tob Control 2014; 23: e3.

77 China Statistical Yearbook, 1989-2014. Beijing: China National Bureau of Statistics, 2014
78 China Tobacco Statistics Yearbook, 1989-2014. Beijing: China National Tobacco Company, 2014.

79 Blecher EH, Van Walbeek CP. Cigarette affordability trends: an update and some methodological comments. Tob Control 2009; 18: $167-75$

80 White JS, Li J, Hu T-w, Fong GT, Jiang Y. The effect of cigarette prices on brand-switching in China: a longitudinal analysis of data from the ITC China Survey. Tob Control 2014; 23: i54-60.

81 Lance PM, Akin JS, Dow WH, Loh C-P. Is cigarette smoking in poorer nations highly sensitive to price? Evidence from Russia and China. J Health Econ 2004; 23: 173-89.

82 Schane RE, Ling PM, Glantz SA. Health effects of light and intermittent smoking: a review. Circulation 2010; 121: 1518-22.

83 Cherukupalli R. A behavioral economics perspective on tobacco taxation. Am J Public Health 2010; 100: 609-15.

84 Gruber J, Kőszegi B. Is addiction "rational”? Theory and evidence. QJ Econ 2001; 116: 1261-303.

85 Gruber J, Mullainathan S. Do cigarette taxes make smokers happier? Top Econ Anal Pol 2005; 5: 1538-653.

86 Gruber J, Kőszegi B. A modern economic view of tobacco taxation. Paris: International Union Against Tuberculosis and Lung Disease, 2008.

87 Jamison DT, Evans JR, King T, Porter I, Prescott N, Prost A. China, The Health Sector. Washington, DC: The World Bank, 1984. 